\title{
FREQUENCY OF COMPLICATIONS IN PAROTID SURGERY.
}

1. MBBS, MS Surgery Associate Professor Department of General Surgery Liaquat University of Medical and Health Sciences Jamhsoro.

2. MBBS, MS Surgery

Assistant Professor

Department of General Surgery

Baqai Medical University Karachi.

3. MBBS, MS Surgery

Associate Professor

Department of General Surgery

Liaquat University of Medical and

Health Sciences Jamhsoro.

4. MBBS, MS Surgery

Medical Officer

Kumar Clinic Akber-e-Azam Road

Umerkot Disst. Umerkot.

Correspondence Address:

Dr. Sadaf lqbal

Department of General Surgery

Baqai Medical University Karachi.

drsadafiqbalkhi@gmail.com

Article received on:

31/12/2018

Accepted for publication:

15/04/2019

Received after proof reading:

25/06/2019

\begin{abstract}
Agha Taj Mohammed ${ }^{1}$, Sadaf Iqbal ${ }^{2}$, Rasool Bux Behan ${ }^{3}$, Jai kumar Malhi ${ }^{4}$
ABSTRACT... To determine the frequency of complications in parotid surgery at tertiary care hospital Hyderabad. Study Design: Cross-sectional study. Setting: Liaquat University, Hyderabad in the Department of General Surgery. Period: August 2016 to December 2017. Materials and Methods: We performed retrospective analysis of 43 patients undergoing parotidectomy. All patients undergoing parotidectomy during this time period were followed up for any post-operative complications. Results: A total of 43 patients met or criteria and were reviewed for the study. Amongst them there 31 males and 12 females. $79 \%$ of patients had benign parotid tumor while $20.9 \%$ had malignant lesion of parotid. Out of 43 patients, $41.8 \%$ $(n=18)$ patients presented with post-operative complications. The most common complication after parotidectomy was facial palsy. Facial palsy was found in $18.6 \%(n=8)$ patients. Upon follow-up and treatment, 5 patients improved whereas patients had permanent facial palsy. Conclusion: Most of the lesions of parotid are of benign aetiology, superficial lobe is most commonly involved. Few complications are involved with parotidectomies and facial nerve palsy is the most common complications. With surgical expertise and use of nerve detector, its incidence can be reduced. Other complications of the surgery should be managed at the earliest to prevent damage.
\end{abstract}

Key words: $\quad$ Complications, Parotid Surgery, Parotidectomy, Facial Nerve Injury.

Article Citation: Mohammed AT, lqbal S, Behan RB, Malhi JK. Frequency of complications in parotid surgery. Professional Med J 2019; 26(7):1032-1035. DOI: 10.29309/TPMJ/2019.26.07.3044

\section{INTRODUCTION}

Parotidectomy is a very common surgery being performed for a wide range of salivary gland tumours. The most frequent indication for parotidectomy were pleomorphic adenoma and metastatic cutaneous squamous cell carcinoma. ${ }^{1}$ Around $80 \%$ of Parotid tumors are benign, most common histological subtype is pleomorphic adenoma. Other common histological subtypes are Warthin's tumor and basal cell adenomas. ${ }^{2}$ Previously in the early twentieth century, intracapsular enucleation was performed for benign parotid tumors. With this technique the capsule was opened, tumor excised, and tumor cells would spread to entire operative field. According to studies conducted, this surgical technique had $20-45 \%$ chance of cancer recurrence. ${ }^{3}$ Parotid surgery gained attention in 1960's when it was found that 19\% of masses are deep lobe tumors in the plane of facial nerve. Selective deep lobe parotidectomies were attempted with maximum conservation of deep lobe but this technique wasn't successful. It was also found that deep lobe tumor surgeries are linked with higher rate of temporary facial nerve dysfunction. ${ }^{4}$ Methylene blue staining of the lesion provides better view for resection and use of nerve detector during surgery decrease the rate of post-operative complications. Parotid surgery by this technique should be practiced by young surgeons during their training. ${ }^{5}$ Parotid neoplasms account for $2 \%$ of head and neck tumors, most of which are benign. Despite recent advancement in techniques, even surgery for benign parotid tumors has comparatively high rate of complications. The overall morbidity after parotidectomy has only been addressed in few studies with limited number of patients. ${ }^{6}$ Retrospective cohort studies have reported that incidence of temporary facial nerve palsy varies from $18 \%$ to $65 \%$, whereas incidence of permanent facial nerve palsy varies from $0 \%$ to 
$19.6 \% .^{7}$ This variation can be explained by different operative techniques and timing of appearance of complication. Most important limitation for assessment of complication is the lack of one standard method for identifying degree of facial nerve damage. Also other factors associated with parotidectomy contribute to complications. ${ }^{8}$ Apart from facial nerve damage, other common complications associated with parotidectomy are fistula formation, Frey's syndrome, infection and sialocele. ${ }^{9}$ All these complications have reported biases due to individual reporting biases and unstandardized methods of severity. ${ }^{10}$ The extent of parotidectomy and type of lesion are the most important predictors for post-operative facial nerve palsy, other contributors being advanced age, size of tumor, and location of lesion. ${ }^{11}$ Duration of surgery expertise of surgeon also affect the extent of facial nerve damage, although its role as a major risk factor remains debatable. Parotidectomies carried by ultrasound knife are known to have increased risk of transient facial nerve palsy. ${ }^{12}$

\section{METHOD}

This is a cross-sectional study conducted in Liaquat University, Hyderabad in the department of general surgery. We performed retrospective analysis of 43 patients undergoing parotidectomy from the duration of August 2016 to December 2017. All patients undergoing parotidectomy during this time period were followed up for any post-operative complications. We reviewed all the cases and identified the cases presenting with post-operative complications. The frequency of complications during parotidectomy was calculated. Data was collected on a semistructured questionnaire and was filled by the investigators themselves.

\section{RESULTS}

A total of 43 patients met or criteria and were reviewed for the study. Amongst them there 31 males and 12 females. Table-I shows the pattern of illness of these patients.

Out of 43 patients, $41.8 \% \quad(n=18)$ patients presented with post-operative complications. Table-Il shows the frequency of complications after parotidectomy. The most common complication after parotidectomy was facial palsy. Facial palsy was found in $18.6 \%(n=8)$ patients. Upon followup and treatment, 5 patients improved whereas patients had permanent facial palsy.

\begin{tabular}{|c|c|}
\hline Pattern of Illness & Percentage (n) \\
\hline Benign & $79 \%$ (34) \\
\hline malignant & $20.9 \%$ (9) \\
\hline
\end{tabular}

\begin{tabular}{|l|c|}
\hline \multicolumn{1}{|c|}{ Complication } & Frequency \\
\hline Haemorrhage & $1(2.32 \%)$ \\
\hline Hematoma & $1(2.32 \%)$ \\
\hline Facial palsy & $8(18.60 \%)$ \\
\hline Parotid fistula & $1(2.32 \%)$ \\
\hline Frey's syndrome & $3(6.97 \%)$ \\
\hline Hypaesthesia of ear lobule & $4(9.30 \%)$ \\
\hline \multicolumn{2}{|c|}{ Table-II. Complications after parotidectomy $\mathbf{n = 4 3}$} \\
\hline
\end{tabular}

\section{DISCUSSION}

Around $80 \%$ of parotid tumors are benign and most common is pleomorphic adenoma. Others are Warthin's tumor, monomorphic adenoma, oncocytoma, hemangioma and lymphoma. Most common malignant tumors of parotid are adenoid cystic carcinoma, acinic cell tumor and lymphoma. Benign parotid tumors are slow growing and asymptomatic until it produces visible swelling and mass effects. Signs suggesting malignancy and other granulomatous diseases are pain, rapid enlargement of swelling and involvement of facial nerve. ${ }^{13}$ The mean duration from presentation of lesion to the surgery is 2.2 years according to a cohort study done.

Also it was shown that females were affected more than males in different studies. ${ }^{14}$ FNAC has been recommended as the most safe, inexpensive and patient friendly investigation for parotid pathology. It has a diagnostic accuracy of more than $70 \%$, moreover it can be done as an outpatient procedure with minimum anaesthesia. Open biopsy of parotid has become obsolete now to potential seeding of malignant cells, facial nerve damage and risk of fistula formation. ${ }^{15}$ Patient's expectation about post-operative are challenging for the surgeon as for most benign lesions, patients expect normal function after 
surgery. Hypaesthesia of greater auricular nerve is present in $20 \%$ of cases, this improves in one year in majority of the cases. ${ }^{16}$ Post-operative facial nerve damage is the earliest complication of parotidectomy, transient paralysis resolves in six months with $85 \%$ recovery in one month after surgery. Sialocele forms if saliva leakage is present from the resected edge of parotid gland under the flap. Further if the inflammatory process continues, it forms salivary fistula. These complications are common and can be treated well by conservative management. Sialocele can be managed by repeated aspirations, pressure dressings and antibiotics. ${ }^{6}$ Hematoma formation is a relatively uncommon complication and is usually associated with per-operative bleeding and rough tissue handling. ${ }^{17}$ In facial nerve dysfunction, marginal mandibular nerve is damaged in $90 \%$ of cases, whereas zygomatic branch is involved in $54 \%$ of cases. Even after preservation of facial nerve, facial nerve dysfunction is present. This can be due to compression and stretching of the nerve during surgery.

Another theory proposed that it can be due to ischemic injury to the nerve during dissection. ${ }^{18}$ Evaluation of facial nerve function is seldom described in previous studies, nor site of nerve injury described. Advancement in surgical approaches from total parotidectomies to conservative surgical techniques over the years, so complication rates are not comparable. ${ }^{10}$ Incidence of Frey's syndrome varies from 0 to $66 \%, 15 \%$ being the most severe presentations. Its diagnosis can be highly variable depending on the individual assessment bias and evaluation methods. Frey's syndrome is due to reinnervation between damaged auriculotemporal branch and sympathetic sweat eccrine glands. Long term follow-up after parotidectomy is required to calculate the incidence of Frey's syndrome. ${ }^{19}$

\section{CONCLUSION}

Most of the lesions of parotid are of benign aetiology, superficial lobe is most commonly involved. Few complications are involved with parotidectomies and facial nerve palsy is the most common complications. With surgical expertise and use of nerve detector, its incidence can be reduced. Other complications of the surgery should be managed at the earliest to prevent damage.

Copyright(C) 15 Apr, 2019.

\section{REFERENCES}

1. Bova R, Saylor A, Coman WB. Parotidectomy: Review of treatment and outcomes. ANZ journal of surgery. 2004; 74(7):563-8.

2. Koch $\mathrm{M}$, Zenk J, Iro H. Long $\square$ term results of morbidity after parotid gland surgery in benign disease. The Laryngoscope. 2010; 120(4):724-30.

3. Klintworth N, Zenk J, Koch M, Iro H. Postoperative complications after extracapsular dissection of benign parotid lesions with particular reference to facial nerve function. The Laryngoscope. 2010; 120(3):484-90.

4. Ikoma R, Ishitoya J, Sakuma Y, Hirama M, Shiono O, Komatsu M, et al. Temporary facial nerve dysfunction after parotidectomy correlates with tumor location. Auris Nasus Larynx. 2014; 41(5):479-84.

5. Vaiman M, Abuita R, Jabarin B. Selective deep lobe parotid surgery for benign tumors. Acta otolaryngologica. 2015; 135(12):1319-22.

6. Thahim K, Udaipurwala $\mathrm{IH}$, Kaleem M. Clinical manifestations, treatment outcome and postoperative complications of parotid gland tumoursan experience of 20 cases. J Pak Med Assoc. 2013; 63(12):1472-5.

7. Papadogeorgakis N, Kalfarentzos EF, Vourlakou C, Malta F, Exarhos D. Simultaneous pleomorphic adenoma of the left parotid gland and adenoid cystic carcinoma of the contralateral sublingual salivary gland: $A$ case report. Oral and maxillofacial surgery. 2009; 13(4):221.

8. Guntinas $\square$ Lichius $\mathrm{O}$, Klussmann JP, Wittekindt C, Stennert E. Parotidectomy for benign parotid disease at a university teaching hospital: Outcome of 963 operations. The Laryngoscope. 2006; 116(4):534-40.

9. Guntinas-Lichius O, Gabriel B, Peter Klussmann J. Risk of facial palsy and severe Frey's syndrome after conservative parotidectomy for benign disease: Analysis of 610 operations. Acta oto-laryngologica. 2006; 126(10):1104-9.

10. Ruohoalho J, Mäkitie AA, Aro K, Atula T, Haapaniemi $A$, Keski-Säntti $H$, et al. Complications after surgery for benign parotid gland neoplasms: A prospective cohort study. Head \& neck. 2017; 39(1):170-6. 
11. Musani MA, Zafar A, Suhail Z, Malik S, Mirza D. Facial nerve morbidity following surgery for benign parotid tumours. J Coll Physicians Surg Pak. 2014; 24(8):56972.

12. Witt RL, Rejto L. Pleomorphic adenoma: Extracapsular dissection versus partial superficial parotidectomy with facial nerve dissection. Delaware medical journal. 2009; $81(3): 119-25$.

13. Morais MdLSd, Azevedo PR, Carvalho $\mathrm{CH}$, Medeiros L, Lajus T, Costa AdLL. Clinicopathological study of salivary gland tumors: An assessment of $\mathbf{3 0 3}$ patients. Cadernos de saude publica. 2011; 27(5):103540.

14. Ito $\mathrm{F}$, Ito $\mathrm{K}$, Vargas $\mathrm{P}$, De Almeida O, Lopes $\mathrm{M}$. Salivary gland tumors in a Brazilian population: $A$ retrospective study of 496 cases. International journal of oral and maxillofacial surgery. 2005; 34(5):533-6.
15. Hartimath B, Kudva A, Rathore AS. Role of fine-needle aspiration cytology in swellings of the parotid region. Indian Journal of Surgery. 2011; 73(1):19-23.

16. Marchese-Ragona R, De Filippis C, Marioni G, Staffieri A. Treatment of complications of parotid gland surgery. Acta Otorhinolaryngologica Italica. 2005; 25(3):174.

17. Musani MA, Sohail Z, Zafar A, Malik S. Morphological pattern of parotid gland tumours. J Coll Physicians Surg Pak. 2008; 18(5):274-7.

18. Dulguerov P, Marchal F, Lehmann W. Postparotidectomy facial nerve paralysis: Possible etiologic factors and results with routine facial nerve monitoring. The Laryngoscope. 1999; 109(5):754-62.

19. Flint PW, Haughey BH, Niparko JK, Richardson MA, Lund VJ, Robbins KT, et al. Cummings OtolaryngologyHead and Neck Surgery E-Book: Head and Neck Surgery, 3-Volume Set: Elsevier Health Sciences; 2010.

\begin{tabular}{|c|c|c|c|}
\hline \multicolumn{4}{|c|}{ AUTHORSHIP AND CONTRIBUTION DECLARATION } \\
\hline Sr. \# & Author-s Full Name & Contribution to the paper & Author $=$ s Signature \\
\hline 1 & Agha Taj Mohammed & $\begin{array}{l}\text { Concept and design, Statistical } \\
\text { expertise, Critical revision of the } \\
\text { article for important intellectual } \\
\text { content. }\end{array}$ & \\
\hline 2 & Sadaf Iqbal & $\begin{array}{l}\text { Data collection, Critical revision } \\
\text { of the article for important } \\
\text { intellectual content. }\end{array}$ & 2058,86 \\
\hline 3 & Rasool Bux Behan & Drafting of the article. & \\
\hline 4 & Jai kumar Malhi & Data collection & \\
\hline
\end{tabular}

